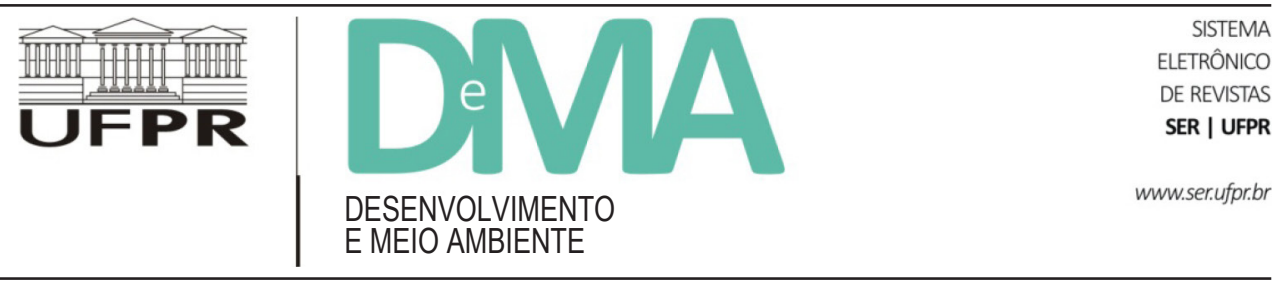

\title{
Epistemologia da agroecologia: dialética versus positivismo
}

\section{Epistemology of Agroecology: Dialectics versus Positivism}

\author{
Alceu Ravanello FERRARO ${ }^{1 *}$ \\ ${ }^{1}$ Programa de Pós-Graduação em Educação, Universidade Federal do Rio Grande do Sul (UFRGS), Porto Alegre, RS, Brasil. \\ *E-mail de contato: aferraro@ufrgs.br
}

Artigo recebido em 26 de setembro de 2014, versão final aceita em 10 de agosto de 2015.

RESUMO Este artigo apresenta duas perspectivas epistemológicas situadas em polos opostos, o positivismo e a dialética marxista, tendo como horizonte o almejado diálogo das ciências da sociedade com as ciências da natureza que constituem o núcleo da agroecologia (a agronomia e a ecologia). Primeiro, destaca as ideias fundamentais do positivismo e analisa suas principais vertentes: o positivismo utópico-revolucionário de Condorcet, o utópico-socialista de Saint-Simon, o conservador de Comte, o utilitarista de Stuart Mill e Spencer, o sociológico de Durkheim e, finalmente, o de Popper, que rejeita a pecha de positivista. Passa, depois, a apresentar como alternativa a perspectiva epistemológica da dialética marxista, que moveu a crítica mais radical ao positivismo, contrapondo a noção de movimento à de ordem, a noção de historicidade das leis econômicas e sociais à de presunção de leis naturais da produção, a de peculiaridade das ciências da sociedade à de concepção de leis sociais naturais, aspectos de fundamental importância para um diálogo produtivo entre ciências sociais e ciências naturais, entre sociedade e natureza, como almejado na agroecologia.

Palavras-chave: agroecologia; epistemologia; positivismo; dialética.

ABSTRACT This article discusses two epistemological perspectives situated in opposite sides: the positivism and the Marxist dialectics, having as its horizon the desired dialogue between the social sciences and the natural sciences that constitute the core of agroecology (agronomy and ecology). It deals first with the fundamental ideas of the positivism and analyses its main lines: Condorcet's utopian-revolutionary one, Saint-Simon's utopian-socialist one, Comte's conservative one, Stuart Mill and Spencer's utilitarian one, the Durkheim's sociological one, and finally, that of Popper, who rejects being described as positivist. The text deals then with the Marxist dialectics as an epistemological alternative, which represented the most radical critique of positivism, opposing the notion of movement to that of order; the notion of historicity of the economic and social laws to the supposition of natural laws of production; the notion of the peculiarity of the social sciences to the conception of natural laws of society, which is considered of great importance for a productive dialogue between social and natural sciences, between society and nature, as it is desired in the agroecology.

Keywords: agroecology; epistemology; positivism; dialectics. 


\section{Introdução}

O tema da epistemologia da agroecologia ${ }^{1}$ tem sido abordado com frequência neste início de século por pesquisadores da área (Carvalho, 2001; Sevilla Gusmán, 2002; Schlindwein et al., 2007; Gomes, 2011; Borsatto \& Carmo, 2012, entre outros). Estes últimos sustentam que a agroecologia identifica o paradigma vigente do positivismo como uma das causas da crise socioambiental e, na busca por alternativas, apontam a Teoria do Pensamento Complexo de Edgar Morin como "um interessante arcabouço filosófico onde a Agroecologia pode se assentar" e a partir da qual se poderia "buscar estabelecer um novo paradigma para se abordar o meio rural" (Borsatto \& Carmo, 2012, p. 713 e 716).

Sevilla Gusmán (2002), por sua vez, num texto sobre a perspectiva sociológica da agroecologia, levanta algumas questões e aponta direções provocativas, entre as quais estão: modificar a parcelização disciplinar; ampliar o enfoque agroecológico no sentido de compreender toda a complexidade de processos tanto biológicos e tecnológicos como socioeconômicos e políticos; levar em conta a natureza pluriepistemológica e dar prevalência a técnicas participativas (pesquisa-ação) de natureza dialética.

Concorda-se com o diagnóstico que vê na vigência do positivismo uma das causas da crise socioambiental. Mas, sem entrar no mérito da teoria da complexidade como alternativa, opta-se por seguir na direção sinalizada por Sevilla Gusmán - a perspectiva dialética. Inicia-se com uma exposição sobre a emergência e constituição da perspectiva positivista, por se entender que o positivismo continua presente de múltiplas formas, para apresentar, então, a perspectiva dialética como alternativa.

Importa dizer ainda que a questão do positivismo se coloca principalmente em relação a como, na agroecologia, se concebe a participação das ciências humanas e sociais aplicadas ${ }^{2}$ reunidas, neste texto, também sob o nome de ciências da sociedade em contraposição a ciências da natureza.

$\mathrm{O}$ interesse pelas duas perspectivas selecionadas tem dupla justificativa. De um lado, como diz Hobsbawm (2008, p. 41), o positivismo, filho tardio das Luzes do século XVIII, foi, além do marxismo, a única corrente ou escola de pensamento voltada à reconstrução da história que exerceu influência no século XIX, devendo-se a ele, principalmente, a introdução, na pesquisa social, de conceitos, métodos e modelos vindos das ciências naturais. De outro lado, a perspectiva dialética, situada no polo oposto, representa, segundo o mesmo autor, a crítica mais radical "das tentativas de assemelhar o estudo das ciências sociais àquele das ciências naturais" (Hobsbawm, 2008, p. 47-48).

Mas o positivismo tem várias caras e pode ser encontrado em tradições culturais diferentes:

Na França, inseriu-se no racionalismo, que vai de Descartes ao iluminismo; na Inglaterra, se desenvolveu inserindo-se na tradição empirista e utilitarista e, em seguida, entrelaçou-se com a teoria darwiniana da evolução; na Alemanha, assume a forma de cientificismo e de monismo materialista; na Itália, com Ardigò, aprofunda suas raízes no naturalismo renascentista, embora dê seus maiores frutos, da situação social da nação recém-unificada, no campo da pedagogia e também na antropologia criminal. (Reale \& Antiseri, 1991, p. 296).

Estas e outras diferenças de origem, de conteúdo e de trajetória não impedem, porém, que esses diferentes positivismos mantenham entre si laços de unidade que permitem situá-los dentro da mesma perspectiva epistemológica.

Neste artigo, o objeto de atenção é particularmente a questão da relação e das condições de diálogo entre

\footnotetext{
${ }^{1}$ Trabalho desenvolvido com apoio do Conselho Nacional de Desenvolvimento Científico e Tecnológico - CNPq.

${ }^{2}$ Classificação do Conselho Nacional de Desenvolvimento Científico e Tecnológico (CNPq), que distingue entre ciências humanas (filosofia, sociologia, antropologia, ciência política, educação etc.) e ciências sociais aplicadas (economia, demografia, direito etc.).
} 
ciências da sociedade e ciências da natureza no domínio da agroecologia, com atenção especial para a perspectiva $^{3}$ do positivismo e, como alternativa, a perspectiva da dialética marxista.

\section{O positivismo}

\subsection{Ideias fundamentais e gênese do positivismo}

Sarup (1980, p. 42) diz que, segundo a opinião geral, os princípios do positivismo são os três a seguir: que não há dicotomia entre o mundo físico e o mundo humano; que os tipos de explicação e descrição nas ciências naturais não diferem dos existentes no mundo social; e que todos os conceitos nas ciências sociais podem ser "reduzidos" ou traduzidos na linguagem das ciências naturais.

De maneira semelhante, Löwy (1985, p. 35-36) também resume em três as ideias fundamentais do positivismo. A primeira está na própria hipótese fundamental de que a sociedade humana é regulada por leis naturais. Dessa hipótese seguem, como segunda e terceira ideias, a conclusão epistemológica que afirma que "os métodos e procedimentos para conhecer a sociedade são exatamente os mesmos que são utilizados para conhecer a natureza" e a conclusão de que, "da mesma maneira que as ciências da natureza são ciências objetivas, neutras, livres de juízos de valor, de ideologias políticas, sociais e outras, as ciências sociais devem funcionar exatamente segundo esse modelo de objetividade científica".

Visto em sua origem e trajetória europeia, em especial francesa, o positivismo é, quanto à sua origem, filho legítimo da filosofia das luzes, do enciclopedismo do século XVIII. Como o enciclopedismo, também o positivismo teve, num primeiro momento, um caráter utópico enquanto "uma visão do mundo de dimensão utópica, crítica e, até certo ponto, revolucionária", sendo que o primeiro teórico a formulá-lo de maneira mais precisa foi o marquês de Condorcet, e o primeiro a usar o termo "positivo" (e.g. ciência positiva) foi o conde de Saint-Simon (Löwy, 1985, p. 37-38). Note-se que Saint-Simon teve Condorcet como mestre e Auguste Comte como secretário, discípulo e, em seguida, renhido antagonista. Assim, não seria correto datar de Auguste Comte o positivismo.

\subsection{Condorcet (1743-1794): o positivismo utópico-revolucionário}

O positivismo utópico-revolucionário teve sua expressão máxima no revolucionário francês Marie Jean Antoine de Caritat, marquês de Condorcet. A importância deste autor hoje, no Brasil, pode ser avaliada pela tradução e publicação de várias obras suas desde o início dos anos 1990. São elas: Sobre a admissão das mulheres ao direito de cidadania (Condorcet. In: Badinter, 1991); Esboço de um quadro histórico do progresso do espírito humano (Condorcet, 1993); Cinco memórias sobre a instrução pública (Condorcet, 2008); Escritos sobre a instrução pública (Condorcet, 2010).

Membro de várias academias de ciências na França e em outros países, Condorcet pode ser considerado também, se não fundador, pelo menos destacado precursor da ciência da sociedade que, com Comte, levaria o nome "física social" e, a seguir, "sociologia". Merecem destaque alguns elementos sobre a concepção dessa nova ciência em Condorcet. É no último capítulo de Esboço..., que ele expõe com clareza a ideia de uma ciência da sociedade à semelhança das ciências da natureza:
Se o homem pode predizer com uma segurança quase integral os fenômenos dos quais conhece as leis; se, mesmo quando estas lhe são desconhecidas, ele pode, a partir da experiência do passado, prever com uma grande probabilidade os acontecimentos do futuro; por que ver-se-ia como um empreendimento quimérico aquele de traçar, com alguma verossimilhança, o quadro

\footnotetext{
${ }^{3}$ No dizer de Marshall (1998, p. 476), o conceito de paradigma de Kuhn "revolucionou o pensamento no campo da filosofia da ciência". Mesmo assim, tendo em vista os questionamentos levantados, entre outros, por Assis (1993) e Berthelot (2000), optou-se por utilizar neste trabalho o termo perspectiva em vez de paradigma. A respeito, pode-se consultar A estrutura das revoluções cientificas, de Kuhn (1992).
} 
dos destinos futuros da espécie humana, a partir dos resultados de sua história? (Condorcet, 1993, p. 176)

Por que seu interesse por uma ciência da sociedade? Como última grande expressão do iluminismo, Condorcet acreditava que o conhecimento das leis que regulam a sociedade ajudaria a resolver as três grandes questões a que, no seu entendimento, se reduziam os destinos futuros da espécie humana: a destruição da desigualdade entre as nações, os progressos da igualdade em um mesmo povo e o aperfeiçoamento real do homem (Condorcet, 1993, p. 176). Se todos os liberais se parecem, também há distinções entre eles. Em sua maioria, os teóricos liberais do século XVIII, como Mandeville (2001) e Smith (1987; 1989), e particularmente a categoria de economistas que Marx (1998, p. 24) identificava como "astutos, ambiciosos e práticos", engajados "sob a bandeira de Bastiat"4, também chamados por ele de praticantes da "economia vulgar" (Marx, 1994, p. 939), punham toda a ênfase no princípio revolucionário da liberdade. Condorcet, ao contrário, tinha como valor central o princípio revolucionário da igualdade. A citação seguinte atesta que, quando falava em igualdade, esse autor referia-se à igualdade material ou real:

Percorrendo a história das sociedades, teremos tido a ocasião de mostrar que frequentemente existe um grande intervalo entre os direitos que a lei reconhece aos cidadãos e os direitos dos quais eles têm um desfrute real; entre a igualdade que é estabelecida pelas instituições políticas e aquela que existe entre os indivíduos. (Condorcet, 1993, p. 182)

As desigualdades tinham, para Condorcet (1993, p. 182), três causas principais: a desigualdade de riqueza; a desigualdade de situação entre aquele cujos meios de subsistência se transmitem à sua família e aquele para quem estes meios dependem da parte de sua vida em que é capaz de trabalhar; e a desigualdade de instrução. Para o autor, se distribuída de maneira desigual, a instrução contribui para a desigualdade, mas se bem dirigida, "corrige a desigualdade natural das faculdades, em lugar de fortalecê-la, assim como as boas leis remedeiam a desigualdade natural dos meios de subsistência" (Condorcet, 1993, p. 186).

Outro ponto importante na concepção de ciência desse autor é que ele está atento à sua aplicação em benefício dos seres humanos, antecipando, assim, de certa forma, uma concepção de políticas sociais (Condorcet, 1993, p. 183) que só começariam a ser formuladas um século mais tarde, a partir do final do século XIX. Esta preocupação com a aplicação do conhecimento pode ser exemplificada por suas propostas de libertação dos escravos (Condorcet, 1993, p. 178), de acesso das mulheres à cidadania (ao voto) (Condorcet. In: Badinter, 1991, p. 43-52), de acesso universal, para homens e mulheres, a uma instrução pública, gratuita e laica, assim como ao mercado de trabalho (Condorcet, 1993; 2008; 2010).

\subsection{Saint-Simon (1760-1825): o positivismo utópico-socialista}

O segundo nome na corrente do positivismo utópico, agora utópico-socialista mais que revolucionário, é Claude-Henri de Rouvroy, conde de Saint-Simon, também Henri de Saint-Simon, como na obra Du système industriel (Do sistema industrial), de 1821, primeira em que aparece o termo positivo. No prefácio dessa obra, Saint-Simon diz que a crise em que se achava mergulhado o "corpo político" havia já trinta anos consistia essencialmente "na passagem do sistema feudal e teológico para o sistema industrial e científico", e que esse fato geral era um dos fatos fundamentais que deveriam "servir de base para a teoria positiva da política" (Saint-Simon, 1821, p. V) $)^{5}$. Trata-se de volume composto de

\footnotetext{
${ }^{4}$ Pode-se conferir o opúsculo A lei (Bastiat, 1991).

${ }^{5}$ É do autor deste artigo a tradução das citações de Saint-Simon (1821), assim como de Barnes (1948), Calvez (1956), Spencer (1983), Mill (1986), Millizo (1986), Mendras \& Étienne (1996), Tort (1996; 1997), Campbell (1988), Marshall (1998), Mandeville (2001), Hobsbawm (2008) e Bynum (2009).
} 
cartas escritas nos meses de junho de 1820 a janeiro de 1821. Ali, o termo positivo aparece repetidamente, como nas seguintes passagens: "Toda a política positiva está contida na lei das finanças" (p. 86); "franceses ocupados em trabalhos de uma utilidade positiva" (p. 88); "Se a enciclopédia tivesse sido feita por sábios positivos [...], não há dúvida que esses autores teriam aplicado a este trabalho o método que eles empregavam diariamente nas ciências positivas que cultivavam" ( $\mathrm{p}$. 143); "a capacidade intelectual a mais positiva" (p. 151); "ideias positivas" (p. 237); "capacidade teórica positiva", "ciências positivas", "filósofos positivos", "sábios positivos" (p. 243-247); "utilidade positiva" (p. 262); novamente "ciências positivas" (p. 267, 276), "política positiva" (p. 277) e "sábios positivos" (p. 302). Para Saint-Simon, destruídas de forma completa, radical e irrevogável as velhas doutrinas, tornava-se necessária uma "nova doutrina geral apropriada ao estado presente da civilização e das luzes" (p. 238), e o termo positivo era usado na tentativa de expressar essa nova doutrina que ele denominava "doutrina industrial" ou "doutrina filosófica industrial", cabendo aos "filósofos positivos", isto é, aos "homens ocupados na observação e na coordenação das generalidades positivas", a função de desenvolver essa doutrina (p. 243-245).

Senhores, a doutrina que dever servir de base ao sistema industrial não pode evidentemente ser feita por vós. [...] Possuindo um alto grau de capacidade prática, vós não podeis possuir, senhores, a capacidade teórica positiva. Esta é apanágio exclusivo dos sábios dedicados às ciências positivas, quer dizer, dos fisiólogos, dos químicos, dos físicos, dos geômetras. [...] Os legistas, os metafísicos, os literatos que, hoje, são todos mais ou menos metafísicos, não devem ter parte maior neste trabalho do que os teólogos. (Saint-Simon, 1821, p. 243).

Mas quem iria apropriar-se do termo "positivo" e, a partir deste, criar o termo "positivismo" seria o ex-secretário de Saint-Simon, Auguste Comte.

\subsection{Auguste Comte (1798-1857): o positivismo conservador}

Com Auguste Comte, o positivismo muda de direção: de utópico-revolucionário (Condorcet) e utópico-socialista (Saint-Simon), torna-se conservador. O tema do progresso cede prioridade ao tema da ordem (ordem e progresso). Comte considerava Condorcet e Saint-Simon demasiadamente críticos, negativos; com ele, o próprio termo preconceito muda de significado. Como esclarece Löwy (1985, p. 39), enquanto, para o positivismo em sua fase utópica, o termo preconceito servia a uma função revolucionária e crítica (era sempre o preconceito das classes dominantes, o preconceito clerical, absolutista, obscurantista, fanático, intolerante, dogmático), com Comte esse termo muda de significado, passando a designar o preconceito revolucionário de Condorcet, que apoiou a Revolução Francesa, ou o preconceito socialista de Saint-Simon.

Comte define a Física Social, depois chamada por ele de Sociologia, como

a ciência que tem por objeto próprio o estudo dos fenômenos sociais, considerados com o mesmo espírito que os fenômenos astronômicos, físicos, químicos e fisiológicos, isto é, submetidos a leis naturais invariáveis, cuja descoberta é o objetivo especial de suas pesquisas. (In: Moraes Filho, 1989, p. 53).

Para Comte, as ciências haviam se tornado positivas na seguinte ordem: a astronomia, em seguida a física, depois a química e, enfim, a fisiologia, "segundo a ordem natural que deviam seguir para tal fim, isto é, segundo o grau maior ou menor de suas relações com o homem", com tendência a operar-se tal mudança também na filosofia, na moral e na política (In: Moraes Filho, 1989, p. 55). O termo sociologia, em substituição ao termo física social, é proposto "a fim de poder designar por esse nome único esta parte complementar da filosofia natural que 
se relaciona com o estudo positivo do conjunto das leis fundamentais apropriadas aos fenômenos sociais" (In: Moraes Filho, 1989, p. 61-62).

O ranço conservador na teoria comtiana provinha de sua avaliação negativa das revoluções econômicas e políticas do século XVIII e primeira metade do século XIX, particularmente na Inglaterra e, a seguir, na França e em outros países da Europa.

Um dos pontos mais lembrados do positivismo de Auguste Comte é sua teoria dos três estados do desenvolvimento da inteligência humana. Aliás, ele inicia a primeira lição de seu Curso de Filosofia Positiva dizendo que, para explicar convenientemente a verdadeira natureza e o caráter próprio da filosofia positiva, há que lançar primeiramente um olhar geral sobre a marcha progressiva do espírito humano considerado em seu conjunto. O resultado desse olhar foi o que o autor chamou de "grande lei fundamental", assim definida:

Essa lei consiste em que cada uma de nossas concepções principais, cada ramo de nossos conhecimentos, passa sucessivamente por três estados teóricos diferentes: o estado teológico ou fictício, estado metafísico ou abstrato e estado científico ou positivo. Em outros termos, o espírito humano, por sua natureza, emprega sucessivamente, em cada uma de suas investigações, três métodos de filosofar, cujo caráter é essencialmente diferente e mesmo radicalmente oposto: primeiro, o método teológico, em seguida, o método metafísico, finalmente, o método positivo. Daí três sortes de filosofia, ou de sistemas gerais de concepções sobre o conjunto de fenômenos, que se excluem mutuamente: a primeira é o ponto de partida necessário da inteligência humana; a terceira, seu estado fixo e definitivo; a segunda, unicamente destinada a servir de transição (Comte, 1973, p. 9-10).

Menos lembrado que a teoria dos três estados de Auguste Comte (In: Cruz, 1989) é o quadro traçado por Condorcet dos sucessivos progressos do espírito humano, de 1793 (Condorcet, 1993), e é praticamente ignorada a teoria dos quatro estágios de Saint-Simon (1821, p. 268-310) em sua Carta aos Filantropos. Assim, a teoria dos estados, estágios ou etapas do progresso ou desenvolvimento do espírito humano é um elemento essencial de todo o positivismo francês, pelo menos de Condorcet até Comte, não apenas do positivismo comtiano.

Entende-se que a diferença mais marcante entre o positivismo de Comte e o de Condorcet está na noção de progresso e no lugar que este tem ocupado na história humana. Comte não nega o progresso, mas submete-o à ordem ou ao "restabelecimento da ordem", como diz Benoit (1999, p. 195. Grifo da autora). Essa diferença de enfoque entre os dois autores é assim sintetizada:

O progresso almejado pela teoria iluminista de Condorcet colocava-se como utopia no horizonte de transformações políticas quanto à igualdade ainda não existente; o progresso pensado pelo positivismo [de Comte] coloca-se como o já consumado e, portanto, inscreve-se no horizonte epistemológico bem-restrito dos objetos estáticos de uma suposta "ciência positiva" da sociedade. (Benoit, 1999, p. 196. Grifo da autora).

\subsection{John Stuart Mill (1806-1873): o positivismo utilitarista inglês}

Até aqui se tratou do positivismo na França, mas este não é o único. $\mathrm{O}$ autor britânico mais lembrado neste ponto é John Stuart Mill, da tradição iluminista escocesa e contemporâneo de Comte. Filósofo, economista, teórico moral e cientista político, foi influenciado em sua formação tanto pelo empirismo britânico de Locke, Berkeley e Hume, como pelo utilitarismo de Bentham e de seu próprio pai, o economista James Mill. Outra influência poderosa sobre Mill partiu do positivismo francês, mas, ao que parece, mais do saintsimonismo do que do comtismo (Mill, 1986, p. 204). A julgar pelo que o autor diz em sua Autobiografia, a influência recebida de Saint-Simon e sua escola antecedeu em uma década e foi muito mais forte do que a proveniente de Auguste Comte:

Os escritores que, mais que os outros, me inculcaram uma nova modalidade de pensamento político foram os da escola saintsimoniana da França. Em 1829 e 1830 tomei conhecimento de alguns de seus escritos. [...] Estavam 
apenas começando a questionar o princípio da propriedade hereditária. De nenhum modo estava eu preparado para acompanhá-los tão longe; porém me impressionou muito sua visão da ordem natural do progresso humano, coisa que eles me apresentaram pela primeira vez, e especialmente a sua divisão da História em períodos orgânicos e períodos críticos. (Mill, 1986, p. 166).

Mill (1986, p.167-168) diz ainda que seu interesse por Comte cessou quando este se afastou dos saintsimonianos; quanto a estes, ele diz que "continuou cultivando-os".

Mas onde está o positivismo de Mill? Na citação anterior, está onde ele diz haver ficado muito impressionado com a visão dos saintsimonianos "da ordem natural do progresso humano". Mais claramente ainda, onde o autor diz que foi sua mulher, Harriet Taylor, que lhe permitiu fazer a distinção adequada "entre as leis da Produção da Riqueza, que são verdadeiras leis naturais que dependem das propriedades dos objetos, e os modos de distribuição da riqueza, que estão sujeitos a certas condições e dependem da vontade dos homens" (Mill, 1986, p. 236).

Em suma, um positivista: as leis da produção capitalista são, para Mill, verdadeiras leis naturais. No entanto, seria um equívoco querer enclausurar no rótulo de "positivista" um intelectual e homem de ação, que lutou pela "melhoria da humanidade" através de objetivos inteligíveis e concretos, tais como:

a abolição do privilégio e do abuso; a luta contra a barbárie elitista e também contra a barbárie popular; o reconhecimento das dignidades básicas dos seres humanos, homens e mulheres por igual; o direito universal ao sufrágio; a abolição da escravidão e do racismo; a supressão do castigo corporal; o direito ao trabalho; o respeito à legítima vontade de independência dos povos contra o centralismo colonialista; a extirpação do preconceito. (Millizo. In: Mill, 1986, p. 21).

Enfim, como os liberais clássicos que o haviam antecedido, Mill sustentava que a produção era regida por leis naturais. Mas também foi capaz de transitar "de um liberalismo individualista até regiões cada vez mais próximas ao corporativismo e ao socialismo", contra os quais polemizara com ardor em seus anos de juventude (Millizo. In: Mill, 1986, p. 23).

\subsection{Herbert Spencer (1820-1903): ainda o posi- tivismo utilitarista inglês}

A concepção utilitarista de Herbert Spencer (1983, p. 29) transparece já no título do primeiro capítulo de seu livro Ensaios sobre Pedagogia: "Que conhecimentos são mais úteis?”. Roupas para vestir-se são mais úteis que tintas para pintar-se, embora se saiba que "a ideia de adornar-se se sobrepõe, entre os selvagens, à ideia de vestir-se":

Humbold refere que o índio do Orinoco trabalhará durante quinze dias para conseguir cores, graças às quais espera ser admirado, e a mesma mulher que não vacilaria em sair completamente nua de sua cabana não de atreveria a incorrer em infração tão grande da moda como a de sair sem estar pintada. (Spencer, 1983, p. 29).

Na sequência, o autor faz mais duas observações reveladoras dessa concepção utilitarista. Uma, que essa correlação existe também no campo intelectual, onde "o gosto pelo decorativo não cede o passo ao uso do útil"; a outra, que "este paralelo é ainda mais exato com respeito ao outro sexo" (Spencer, 1983, p. 30-31).

Quanto à sua posição positivista, há uma novidade. Se em Comte a ciência da sociedade, depois chamada de sociologia, era pensada como uma física social, em Spencer ela é pensada como uma biologia social, regida por leis típicas de uma evolução superorgânica, isto é, de um evolucionismo social.

Opondo-se a Comte, o autor diz que "existem duas grandes categorias de agregados a que se poderá comparar o agregado social, os inorgânicos e os orgânicos". Diz ainda que a sociedade, sendo "um todo constituído por partes vivas não pode assemelhar-se nas suas características gerais a todos sem vida". Assim, "as relações permanentes entre as partes duma sociedade são análogas 
às relações permanentes que existem entre as partes de um organismo vivo" (Spencer. In: Cruz, 1989, I, p. 185 192. Grifo do autor).

Se Darwin (2009) falava em evolução das espécies, referindo-se aos reinos animal e vegetal, e se Comte tinha uma concepção idealista da evolução, expressa na lei dos três estados, como dito anteriormente, em Spencer tem-se uma concepção naturalista da evolução das sociedades humanas, cujo modelo é o próprio crescimento orgânico. A verdade é que aquilo que fora pensado inicialmente como uma analogia orgânica passou a ser visto como realidade: "a sociedade é um organismo", diz Spencer (In: Cruz, 1989, I, p. 193), passando assim da analogia orgânica para o organicismo - a sociedade concebida, não à semelhança de, mas como um organismo.

Note-se que, como se disse antes, na Inglaterra o positivismo se desenvolveu inserindo-se na tradição empirista e utilitarista e, em seguida, entrelaçando-se com a teoria darwiniana da evolução (Reale \& Antiseri, 1991, p. 296). Herbert Spencer é a concepção mais acabada dessa tendência. Seu conceito de evolução social faz de Spencer o verdadeiro artífice do assim chamado "darwinismo social" (Ferraro, 1999; 2005; Tort, 1996; 1997), que tem pouco ou nada a ver com a teoria darwiniana da origem das espécies, relativa aos mundos vegetal e animal (Darwin, 2009). Segundo Tort (1997, p. 66-67), o darwinismo social foi coisa de Spencer, ou, mais precisamente, foi uma construção do "concorrencialismo liberal" que reinava sobre as mentalidades dos grandes atores e baluartes do industrialismo vitoriano, que resultou numa confusão entre conceitos e teorias, a ponto de o próprio Darwin ter passado a ser lido "através da luneta de Spencer". Segundo o mesmo autor, foram "certas evidências" colhidas de $A$ origem das espécies de Darwin que, "exportadas da biologia para a análise dos 'organismos sociais", deram origem a esse "desvio organicista" a que se deu, de maneira ilegítima, o nome de "darwinismo social" (Tort, 1996, p. 69). O mesmo foi sustentado, mais recentemente, na Introdução à edição comemorativa dos 150 anos de $A$ origem das espécies:

Trabalhando independentemente de Darwin, Herbert Spencer (1820-1903) usou a evolução como a base de toda uma série de trabalhos na filosofia, psicologia, sociologia e antropologia. O que ficou conhecido como "darwinismo social" era, na realidade, "spencerismo social", porquanto fora Spencer quem empurrara a sua doutrina da sobrevivência do mais apto até os seus limites, na vida social e nacional. (Bynum. In: Darwin, 2009, p. xlvi).

\section{7. Émile Durkheim (1858-1917): tratar os fatos sociais como coisas}

Para Marshall (1998, p. 175), Durkheim é o mais famoso sociólogo francês, reconhecido como o fundador do funcionalismo, "mas mais recentemente saudado por autoridades de peso em estruturalismo, sociolinguística, [...] e pós-modernismo, todos eles tendo achado em escritos de Durkheim ideias e sentimentos que podem ser facilmente incorporados". Isto diz da dificuldade de classificar Durkheim: "Ele leu e absorveu o trabalho de seus contemporâneos próximos, incluindo Karl Marx, o que talvez explique por que o seu pensamento foi pintado de diferentes formas como idealista, realista, positivista e evolucionista." (Marshall, 1998, p. 176).

Afinal, faz sentido situar Durkheim (1858-1917) entre os positivistas? Entende-se que sim, mesmo que Reale \& Antiseri (1991, p. 295-349), por exemplo, não incluam Durkheim no rol de autores e de correntes que constam no longo capítulo por eles dedicado ao positivismo. No entanto, seria um grande equívoco pretender confinar Durkheim ao rótulo de positivista. Onde está, então, mais precisamente, o positivismo desse autor? É o que se tentará mostrar a seguir.

Campbell $(1988$, p. 171, 196) localiza o traço característico do positivismo de Durkheim no fato de ele "enfocar a sociedade como uma realidade orgânica independente que tem suas próprias leis, seu próprio desenvolvimento e sua própria vida", e diz que "muitos de seus críticos têm atacado o que consideram uma adesão obsessiva de Durkheim aos métodos das ciências naturais (o que os seus críticos denominam "cientificismo")".

Ocupando-se de lhe estabelecer a especificidade e autonomia, Durkheim define a tarefa da sociologia como sendo o "tratamento científico dos fatos sociais". E é justamente por isso que, para ele, a sociologia não 
pode limitar-se a ser "paráfrase dos preconceitos tradicionais", devendo-se esperar dela que "mostre as coisas de maneira diferente da encarada pelo vulgo" e que, nas discussões sociológicas, mantenha o senso comum a distância (Durkheim, 1971, p. XV).

No início do primeiro capítulo de As regras do método sociológico, Durkheim diz que, se tal é o objeto da sociologia, "antes de indagar qual o método que convém ao estudo dos fatos sociais, é necessário saber que fatos podem ser assim chamados" (Durkheim, 1971, p.1). E ele os define:

É fato social toda maneira de agir fixa ou não, suscetível de exercer sobre o indivíduo uma coerção exterior; ou então ainda, que é geral na extensão de uma sociedade dada, apresentando uma existência própria, independente das manifestações individuais que possa ter. (Durkheim, 1971, p. 11)

Definido o fato social, objeto da nova ciência, o autor passa à definição das regras relativas à observação dessa nova ordem de fatos. Interessa aqui particularmente esta: "A primeira regra e a mais fundamental consiste em considerar os fatos sociais como coisas." (Durkheim, 1971, p. 13. Grifos do autor). E ele esclarece adiante:

E todavia os fenômenos sociais são coisas e devem ser tratados como coisas. Para demonstrar esta proposição não é necessário filosofar sobre a natureza deles, discutir as analogias que apresentam com os fenômenos dos reinos inferiores. Basta constatar que são eles o único datum oferecido aos sociólogos. Na verdade, é coisa tudo que é dado, tudo que se oferece ou antes se impõe à observação. Tratar fenômenos como coisas, é trata-los na qualidade de data que constituem o ponto de partida da ciência. (Durkheim, 1971, p. 24. Grifos do autor).

No prefácio à segunda edição, Durkheim defende-se da acusação de realismo e ontologismo e tenta explicar-se a respeito da proposição fundamental do seu método ("Os fatos sociais devem ser tratados como coisas"), justamente a que mais tinha provado contestações. "Nossa regra", diz ele, "não implica, pois, nenhuma concepção metafísica, nenhuma especulação a respeito do que há no mais profundo do ser." E prossegue: "O que [essa regra] reclama do sociólogo é que se coloque num estado de espírito semelhante ao dos físicos, químicos, fisiologistas, quando se aventuram numa região ainda inexplorada de seu domínio científico." (Durkheim, 1971, p. XXIII). Aqui está o positivismo de Durkheim: no entendimento de que, no estudo da sociedade, o pesquisador deve proceder como os físicos, químicos, fisiologistas etc.; de que, como estes, também os estudiosos da sociedade devem tratar seu objeto, os fatos sociais, como coisas. Na conclusão de As regras do método sociológico, o autor faz o seguinte reparo: "Mas se consideramos os fatos sociais como coisas, consideramo-los como coisas sociais. Este é o terceiro traço característico de nosso método, que prima em ser exclusivamente sociológico." (Durkheim, 1971, p. 126. Grifo do autor), o que, segundo o autor, não muda em nada a concepção fundamental sobre como se faz ciência: o objeto do conhecimento é variável, podendo ser físico, químico, fisiológico, social ou outro, mas deverá sempre ser tratado como coisa. Para o autor, o fato de se tratar de coisa tal ou qual indica apenas especificidade no campo do conhecimento, não diferença no método do conhecimento.

Cruz (1989, p. XI) sustenta que Durkheim “é ainda um herdeiro do 'objetivismo positivista", porque, para ele, "Sujeito e objeto permanecem ainda [...] distintos e separados, tal como entre os fundadores". Este é também o entendimento de Mendras \& Étienne (1996, p. 94), quando dizem que "Durkheim quer construir a sociologia sobre o modelo das ciências da natureza" e que "as ciências na natureza são antes de tudo ciências das coisas". E ainda: "O método de Durkheim está marcado por seu tempo e pela concepção das ciências da natureza de sua época" (Mendras \& Étienne, 1996, p. 102).

\subsection{Karl Popper (1902-1994): quando o termo positivista vira palavrão}

Filósofo da ciência, austríaco naturalizado britânico e convertido de comunista em liberal, em 1947 Popper, junto com Friedrich A. Hayek, Milton Friedman, Ludwig von Mises e outros, participou da fundação So- 
ciedade de Mont Pelerin, com o propósito de defender o retorno ao liberalismo clássico, do laissez-faire, da não intevenção do Estado, corrente que levaria o nome de neolibealismo.

Mas Karl Popper entra na relação de autores aqui discutidos a propósito da perspectiva positivista por uma razão singular: formado em filosofia na Universidade de Viena, conviveu com figuras expressivas do Círculo de Viena, que reunia os assim chamados positivistas lógicos ou empiristas lógicos; divergiu deles, criticando suas posições, e acusado de positivista, defendeu-se do que para ele era um equívoco, um mito, um rótulo.

No texto Lógica das ciências sociais, Popper (1978, p. 89) diz nunca ter sido membro do Circulo de Viena, que reunia entre seus integrantes alguns amigos seus. Diz, inclusive, nunca ter sido convidado para qualquer reunião desse Círculo, "talvez", acrescenta ele, "devido à minha oposição ao positivismo".

Com efeito, já em seu primeiro livro, A lógica da investigação científica, de 1935, Popper criticara o positivismo, particularmente na forma professada pelo Círculo de Viena. Por exemplo, onde, buscando esclarecer a "diferença profunda" que ele via entre a sua posição e a dos positivistas, dizia: "Não agrada ao positivista a ideia de que possam existir problemas significativos fora do campo da ciência empírica 'positiva' - problemas que seria necessário tratar com uma teoria filosófica genuína." E prossegue: "Não lhe agrada [ao positivista] a ideia de que possa existir uma teoria genuína do conhecimento, uma epistemologia ou uma metodologia. Pretende ver nos problemas filosóficos propostos, simplesmente 'pseudoproblemas' ou 'enigmas"' (Popper, 1980, p. 22).

Mas o que aqui mais interessa é o que se seguiu à conferência de abertura sobre $A$ lógica das ciências sociais, proferida por Popper no Congresso dos Sociólogos Alemães, em Göttingen, no ano de 1961. Ele expressa dupla queixa em relação a professores da "escola 'dialética' de Frankfurt": quanto a Theodor Adorno, haver lido "com ênfase" sua réplica, sem discutir as 27 teses apresentadas por ele, Popper, na conferência; quanto a Jürgen Habermas, havê-lo chamado de "positivista", contra o que protesta Popper (1978, p. 36-37).

Não há dúvida de que Popper foi um crítico do positivismo, pelo menos do positivismo lógico ou empirista do
Círculo de Viena. Em suas “considerações críticas" sobre o livro A disputa do Positivismo na Sociologia Alemã, ele retruca a seus oponentes: "Tudo o que puderam fazer foi rotular-me de 'positivista' (mesmo ao preço de atribuir um nome altamente depreciativo ao debate, no qual nem um único 'positivista' esteve envolvido)" (Popper, 1978, p. 38). Note-se que, para o autor, o termo positivismo virara palavrão: "um nome altamente depreciativo".

Mas pode um crítico do positivismo ser positivista? Não há nada que possa impedir. Afinal, só para exemplificar, Comte foi um crítico do positivismo de Saint-Simon, como se viu antes, e Durkheim (1971, p. 17-18), um crítico do positivismo de Comte assim como daquele de Spencer. Há passagens que apontam para um corte positivista na concepção de Popper sobre as ciências sociais. A passagem que segue parece atestar a presença em Popper de pelo menos duas das três ideias fundamentais que, como se viu antes (Löwy, 1985, p. 35-36), caracterizam o positivismo: que os métodos e procedimentos para conhecer a sociedade são exatamente os mesmos de que se servem os cientistas da natureza, e que as ciências sociais devem funcionar segundo o modelo de objetividade científica das ciências da natureza. Eis o que diz Popper (1978, p. 40):

\begin{abstract}
O que eu combati, principalmente, foi a crença de Mannheim de que existia uma diferença essencial, relativa à objetividade, entre o cientista social e o cientista natural, ou entre o estudo da sociedade e o estudo da natureza. [...] Os cientistas naturais não são mais objetivos do que os cientistas sociais. Nem mais críticos. Se há mais 'objetividade' nas ciências naturais, então é porque existe uma melhor tradição e padrões mais elevados de clareza e criticismo racional.
\end{abstract}

Parece que não seria exagero acrescentar que está subentendida, aí, também a primeira ideia fundamental do positivismo apontada por Löwy: a de que a sociedade é regida por leis naturais.

No entanto, o que interessa aqui não é decidir se Popper é ou não positivista. É, ao contrário, dizer que a influência do positivismo foi tão marcante, desde meados do século XIX, que é possível identificá-lo até em quem o rejeita. 


\section{A agroecologia e o positivismo}

Até aqui, buscou-se situar historicamente a perspectiva teórico-metodológica de produção do conhecimento conhecida pelo nome de positivismo, tendo-se considerado em especial algumas de suas múltiplas versões ou correntes. Destacam-se, a seguir, alguns pontos de interesse da agroecologia, relacionados à questão da relação entre ciências da sociedade e ciências da natureza.

O primeiro ponto é que o positivismo acabou por se configurar como uma espécie de obviedade no discurso sobre a ciência, seja na maneira como nas ciências naturais se concebe a ciência em geral, seja na maneira como nas próprias ciências humanas e sociais aplicadas se pensa a produção do conhecimento nessa grande área.

No que concerne especificamente à participação das ciências da sociedade na agroecologia, deve-se notar que o positivismo pode entrar, aberta ou sorrateiramente, por diferentes portas: de um lado, pelo fato mesmo de os cientistas da natureza tenderem a conceber a participação das ciências da sociedade à semelhança do fazer científico próprio das ciências naturais; de outro, pelo fato de sociólogos, antropólogos, historiadores, cientistas políticos, economistas etc. também conceberem, com frequência, o seu fazer científico à semelhança dos cientistas da natureza.

$\mathrm{O}$ segundo ponto a destacar diz respeito à prática frequente de se identificar métodos quantitativos com positivismo, como se toda quantificação denotasse uma postura positivista, e como se, nos métodos qualitativos, o pesquisador estivesse a salvo do positivismo (Ferraro, 2012). A propósito, vale lembrar aqui a inseparabilidade que existe entre quantidade e qualidade na teoria marxista: "Como valores de uso, as mercadorias são, antes de qualquer coisa, de qualidade diferente; como valores de troca, só podem diferir na quantidade, não contendo, portanto, nenhum átomo de valor de uso." (Marx, 1998, p. 59). É o que acontecia com o próprio casaco de Marx ${ }^{6}$ : enquanto valor de uso, servia para aquecê-lo, bem como para conferir-lhe a distinção necessária para entrar no
Museu Britânico para suas pesquisas, sendo, em ambos os casos, pura qualidade; no entanto, sempre que empenhado em alguma casa de valores em Londres, esse mesmo casaco era pura quantidade: $x$ libras esterlinas para tirar o seu proprietário de algum aperto.

Como terceiro ponto tem-se que a concepção positivista não nega o progresso, mas o tem como algo já atingido, realizado. Ela prioriza, por isso, a ordem. Mudança social, só por evolução social. Sztompka (1998, p. 189-192) aponta 11 características do núcleo comum da teoria evolucionista, entre as quais: o recurso à analogia orgânica para a compreensão da sociedade, entendida esta como um todo orgânico; e a mudança como característica natural, necessária, inescapável, endógena, espontânea, natural (“da 'natureza' mesma da sociedade"), direcional, unilinear, evolucionária, cumulativa, sem descontinuidades ou rupturas radicais, equivalente a progresso.

O termo "evolução", que substituiu a ideia de progresso, remete ao núcleo das teorias de expoentes do positivismo como Comte e Spencer (Barnes, 1948, p. 81-109, 110-137). De um lado, surpreende, assim, que o termo evolução (social, econômica, cultural, entre outras) apareça sem maior discussão, inclusive em trabalhos de cientistas tanto da natureza como da sociedade que se posicionam contra o positivismo. De outro, é compreensível: afinal, a sociologia, por exemplo, além de se haver espelhado, em sua constituição como nova ciência, nas ciências da natureza, especialmente na física e na biologia, valeu-se também de muitas categorias dessas ciências, seguidas do qualificativo "social": física social, átomo social, pressão social, sistema social, organismo social, função social, evolução social etc.

Por fim, holismo é um termo que passou a ser usado com ênfase em alguns estudos agroecológicos, em contraposição a individualismo, mecanicismo, cartesianismo, racionalismo. A esse respeito caberia notar que, como polo oposto ao individualismo metodológico, o "methodological holism" (holismo metodológico) é "o princípio teórico de que cada entidade (grupo, instituição ou sociedade) tem uma totalidade que é distinta e não

\footnotetext{
${ }^{6}$ Ver O casaco de Marx, de Stallybras (1999).
} 
pode ser entendida pelo estudo apenas de seus elementos componentes", tendo-se como exemplo disto a afirmação de Durkheim "de que os fatos sociais podem ser estudados e explicados independentemente do indivíduo" (Marshall, 1998, p. 304). Neste caso, fica a pergunta sobre o que o conceito de totalidade da dialética marxista acrescentaria ao conceito de holismo. Entende-se que o termo "holismo" sugere ordem, harmonia, consenso, integração das partes, enquanto que o termo "totalidade", central na dialética marxista, designa um todo, sim, mas em movimento, dinâmico, permeado de contradições, sujeito a conflitos, rupturas, transformações.

Mas, com isto, já se está entrando na perspectiva dialética.

\section{A dialética como alternativa ao positivismo}

Como se pôde ver até aqui, o positivismo que se impôs quase como senso comum no meio científico está centrado na noção de ordem e no entendimento de que as ciências da sociedade devem ter como modelo as ciências da natureza.

Afastada a perspectiva do positivismo, há que buscar caminho alternativo, o qual, obviamente, não poderá ter como pressupostos nem essa primazia da noção de ordem, nem o entendimento de que a participação das ciências da sociedade na produção do conhecimento na agroecologia deva ter as ciências naturais como modelo. Existe esse caminho? Entende-se que sim, e que o caminho alternativo é a dialética. Não a dialética hegeliana, com a cabeça para o chão, mas a dialética marxista, com a cabeça para o alto ou com os pés no chão.

Em relação à dialética marxista, é interessante notar que o autor de Marx hoje, ao tentar distinguir o que já estava morto e o que continuava vivo em Marx, tenha colocado em primeiro lugar, entre as coisas que, em sua opinião, permaneciam vivas, justamente o método dialético (Elster, 1989, p. 206-219). Isto dito não por um marxista, mas por alguém que desistira de publicar sua tese de doutorado, de 1971, por achar que não haveria público para o livro: de um lado, por imaginar que suas posições metodológicas levariam os leitores a situá-lo na direita - sem chance, portanto, de conquistar o público marxista; de outro, por supor que os não marxistas haveriam de achar excessivo o marxismo ainda presente em sua tese (Elster, 1989, p. 10-11).

Sem espaço para tratar aqui de todo o processo, resultado e implicações do trabalho desenvolvido por Marx na construção do método da economia política (bem como das ciências da sociedade) e na discussão da relação entre ciências da natureza e ciências da sociedade a partir da e em confronto com a dialética hegeliana, opta-se por enfrentar, na sequência, apenas alguns pontos tidos como mais pertinentes.

\subsection{A relação de Marx com a dialética hegeliana}

No Posfácio da segunda edição do livro 1 de $O C a$ pital, Marx diz que seu método dialético difere, por seu próprio fundamento, do método hegeliano, sendo a este inteiramente oposto. Diz também que criticara a dialética hegeliana, no que ela tinha de mistificação, havia já quase 30 anos, numa referência, ali, à obra Ideologia alemã, de 1845, escrita em parceria com Engels. Diz ainda que, ao tempo da elaboração do primeiro livro de O Capital, quando Hegel era dado como um "cão morto", ele se confessara abertamente "discípulo daquele grande pensador". E diz, finalmente, que a mistificação por que passara a dialética nas mãos de Hegel "não o impediu de ser o primeiro a apresentar suas formas gerais de movimento, de maneira ampla e consciente", criticando apenas o fato de a dialética hegeliana estar "de cabeça para baixo", sendo, portanto, necessário "pô-la de cabeça para cima, a fim de descobrir a substância racional dentro do invólucro místico.” (Marx, 1998, p. 28-29).

Um exemplo dessa dialética com os pés no chão, no mundo real, encontramo-lo na discussão sobre método em Miséria da filosofia:

\footnotetext{
A burguesia começa com um proletariado, ele próprio um resto do proletariado dos tempos feudais. No decorrer do seu desenvolvimento histórico, a burguesia desenvolve necessariamente o seu caráter antagônico, que no início se apresenta mais ou menos disfarçado, existindo apenas em estado latente. À medida que a burguesia se desen-
} 
volve, desenvolve-se no seu seio um novo proletariado, um proletariado moderno; desenvolve-se uma luta entre a classe proletária e a classe burguesa, luta que, antes de ser sentida pelos dois lados, entendida, apreciada, compreendida, confessada, e proclamada em voz alta, apenas se manifesta inicialmente por conflitos parciais e momentâneos, por fatos subversivos. Por outro lado, se todos os membros da burguesia moderna têm o mesmo interesse na medida em que formam uma classe perante outra classe, têm interesses opostos, antagônicos, quando colocados uns diante dos outros. Essa oposição de interesses decorre das condições econômicas da vida burguesa. [...] Quanto mais evidente se torna esse caráter antagônico, mais os economistas, os representantes da produção burguesa se embaraçam com a sua própria teoria. (Marx, 2006, p. 109)

Tem-se aí a dialética hegeliana de tese, antítese e síntese, posta por Marx com os pés no chão, no mundo real.

\subsection{Conflito versus consenso, transformação versus ordem}

São conhecidas, especialmente na sociologia, as expressões "teorias do consenso" e "teorias do conflito". Aquelas tendo como protótipo o conceito comtiano de "ordem", de ordem estabelecida; estas tendo como protótipo o conceito marxista de conflito, de movimento, de luta, de contradição, de transformação.

Na décima primeira tese sobre Feuerbach, Marx \& Engels (1987, p. 128. Grifos dos autores) esclarecem bem qual o desafio neste ponto: "Os filósofos se limitaram a interpretar o mundo de diferentes maneiras; mas o que importa é transformá-lo". A perspectiva desses autores não é a da ordem, como no positivismo, mas a da transformação. Transformação que não deve ser confundida nem com o conceito spenceriano de evolução orgânica ou crescimento orgânico, que, segundo ele, se verifica em qualquer tipo de organismo, inclusive na sociedade - que ele tem como um organismo - (Spencer. In: Cruz, 1989, p. 183-231), nem com a concepção de mudança no sentido de simples variação com o tempo e o meio, de mera diversificação, diferenciação ou heterogeneidade, de maleabilidade, de correntes sociais, de adaptação ao meio, como em Durkheim (1967, p. 35, 40-41, 69).

Tem-se coisa semelhante em Miséria da Filosofia, onde Marx dirige crítica contra Proudhon e os economistas. Contra os economistas, o autor argumenta que esses exprimem as relações da produção burguesa (a divisão do trabalho, o crédito, a moeda etc.) "como categorias fixas, imutáveis, eternas”, quando, na realidade, essas categorias "são tão pouco eternas como as relações que exprimem", são "produtos históricos e transitórios", são apenas "as expressões teóricas, as abstrações das relações sociais de produção", relações estas em permanente movimento, porquanto, para ele, "de imutável só existe a abstração do movimento - mors immortalis" (Marx, 2006, p. 94-98. Grifos do autor).

Contra o autor de A Filosofia da Miséria, Marx argumenta que se, de um lado, o sr. Proudhon "compreendeu muito bem que os homens fabricam os tecidos de lã, os tecidos de algodão e os de seda, dentro de determinadas relações de produção", de outro, ele foi incapaz de compreender que "essas relações sociais determinadas são também produzidas pelos homens, da mesma maneira que os tecidos de algodão, de linho etc." (Marx, 2006, p. 98).

Os exemplos poderiam ser multiplicados. Eles apontam para a historicidade das relações sociais burguesas de produção (o modo capitalista de produção), assim como de qualquer ordem estabelecida. Tudo é histórico: "Marx não reconhece a existência de nenhum aspecto da realidade humana situado acima da história ou fora dela." (Konder, 1988, p. 53), podendo, por isso, mudar ou ser transformado, revolucionado. Tudo é movimento, mas movimento no sentido dialético, que envolve não apenas oposição (Gegenzatz), separação (Trennung), mas também contradição (Wiederspruch): contradição dialética, que não pode ser superada por meio especulativo, mas apenas por ato prático, "revolucionando o mundo contraditório e inumano produzido pelos homens", como esclarece Bedeschi (1989, p. 16-23). 


\subsection{Ciências da natureza e ciências da sociedade}

Outro ponto a considerar se refere à relação das ciências da sociedade com as ciências da natureza. Aqui também a dialética marxista se situa no polo oposto ao positivismo. A esse respeito, é de grande interesse o que dizia Marx, já em 1844, sobre a dificuldade de diálogo entre as ciências naturais e a filosofia, coisa que poderia estender-se ao conjunto das ciências humanas e sociais aplicadas:

As ciências naturais desenvolveram uma tremenda atividade e reuniram uma massa sempre crescente de dados. Mas a filosofia permaneceu-lhes estranha, da mesma maneira que as referidas ciências continuaram estranhas à filosofia. A sua aproximação momentânea não passou de uma ilusão fantástica. Nasceu o desejo de união, mas faltou o poder para a levar a cabo." (Marx, 1989, p. 201. Grifos do autor)

Tratando do método, Marx, em sua resposta à Filosofia da miséria de Proudhon, criticava os economistas que, à semelhança dos cientistas da natureza, pensavam a economia como sendo regida por leis naturais da produção:

Os economistas têm um modo estranho de proceder. Para eles existem apenas duas espécies de instituições: as da arte e as da natureza. As instituições do feudalismo são instituições artificiais, as da burguesia são instituições naturais. [...] Dizendo que as relações atuais - as relações da produção burguesa - são naturais, os economistas dão a entender que se trata de relações nas quais se cria a riqueza e se desenvolvem as forças produtivas de acordo com as leis da natureza. Portanto, essas relações são elas próprias leis naturais independentes da influência do tempo. São leis eternas que devem reger sempre a sociedade. (Marx, 2006, p. 107).

No prefácio à primeira edição de $O$ capital, Marx avança na crítica a essa maneira de conceber a economia política como uma ciência natural, mostrando onde está a diferença. "O físico", diz ele, "observa os processos da natureza, quando se manifestam na forma característica e estão mais livres de influências perturbadoras, ou, quando possível, faz ele experimentos que assegurem a ocorrência do processo, em sua pureza" (Marx, 1998, p. 16). Segundo o autor, coisa bem diferente é o que acontece no domínio da economia política, em que a natureza particular da matéria ali versada "levanta contra ela as mais violentas, as mais mesquinhas e as mais odiosas paixões, as fúrias do interesse privado". E exemplifica dizendo que a Igreja Anglicana preferia "absolver uma investida contra 38 dos seus 39 artigos de fé a perdoar um ataque contra 1/39 de suas rendas" (Marx, 1998, p. 18). Tem-se aí o oposto da primeira regra durkheimiana do método sociológico - a de "considerar os fatos sociais como coisas" (Durkheim, 1971, p. 13).

Assim, a dialética de Marx contrapunha-se não só ao idealismo alemão, ao método hegeliano, à dialética "de cabeça para baixo", mistificada; opunha-se também à economia política clássica em seu intento de descobrir as supostas leis naturais, eternas, da produção burguesa. Para Marx, ao contrário das ciências naturais, na economia política não temos leis universais, eternas, mas leis particulares a cada modo de produção, inclusive o capitalista. O que Marx dizia da economia política pode ser estendido ao conjunto das ciências humanas e sociais aplicadas.

O marxista italiano Antonio Gramsci (2001, p. 173), como que se contrapondo à regra durkheimiana de tratar os fatos sociais como coisas, sustenta que "se nem mesmo as verdades científicas são definitivas e peremptórias, também a ciência é uma categoria histórica" (Gramsci, 2001, p. 174), e que, por isso, cada nova ciência tem que construir o seu método, abrir o seu caminho, e não buscá-lo em ciências-fetiche:

\footnotetext{
"Científico". O que é "científico"? O equívoco em torno dos termos "ciência" e "científico" nasceu do fato de que eles assumiram seu significado a partir de um grupo determinado de ciências, precisamente as ciências naturais e físicas. Chamou-se de "científico" todo método que fosse análogo ao método de pesquisa e de exame das ciências naturais, transformadas em ciências por excelência, as ciências fetiche. Não existem ciências por excelência e não existe um método por excelência, "um método em si”. Toda pesquisa científica cria para si um método adequado, uma lógica própria, cuja generalidade
} 
e universalidade consiste apenas em ser "conforme ao fim”. (Gramsci, 2001, p. 234-235)

Em suma, cada nova ciência precisa construir o seu caminho, o seu método. Vale também lembrar a observação do autor de História e consciência de classe sobre o caráter ideológico da ideia de aplicar ao estudo da sociedade o ideal de conhecimento das ciências naturais:

Quando o ideal de conhecimento das ciências naturais é aplicado à natureza, ele serve somente ao progresso da ciência. Porém, quando é aplicado à evolução da sociedade, revela-se um instrumento de combate ideológico da burguesia. Para esta última, é uma questão vital, por um lado, conceber sua própria ordem de produção como constituída por categorias intemporalmente válidas e destinadas a existir sempre graças às leis da natureza e da razão e, por outro lado, julgar as contradições que se impõem ao pensamento de maneira inevitável não como fenômenos pertencentes à essência dessa ordem de produção, mas como simples fenômenos de superfície. O método da economia política clássica encontrou seus limites, enquanto conhecimento científico, nessa estrutura da realidade social e no caráter antagônico da produção capitalista. (Lukács, 2003, p. 80)

O autor de La pensée de Karl Marx (O pensamento de Karl Marx) sustenta que as ciências da natureza são "específicas": elas reconhecem e estudam como tais as polaridades e oposições naturais, físicas, biológicas etc., mas "sem jamais conseguir superar essas oposições", ao passo que a ciência social, ao contrário, "examina [...] as oposições para superá-las" (Calvez, 1956, p. 381. Grifo do autor).

Outro aspecto ressaltado por Calvez (1956, p. 347. Grifos do autor) é a inseparabilidade entre conhecimento e realidade: "Não se pode, por exemplo, dissociar verdadeiramente a prática da dialética no plano do saber e sua prática no [plano do] real. A dialética não quer de fato ser outra coisa que o movimento do real". Daí, segundo o mesmo autor, a dificuldade, não de dissociação, que não teria legitimidade, mas simplesmente de se tratar do método científico separadamente do conteúdo da ciência (Calvez, 1956, p. 247). Apesar de tantos manuais de metodologia em diferentes campos do conhecimento, particularmente nas ciências da sociedade, são raras as aventuras de escrita de manuais sobre método dialético. Aprende-se a dialética marxista no contato com as obras de Marx.

\subsection{Materialismo histórico e concepção de história}

Em seus escritos de crítica da economia política, Marx e Engels inspiraram-se em Hegel - ou no idealismo alemão -, nos economistas clássicos e nos socialistas utópicos. Como já foi dito, de Hegel colheram o método dialético, mas colocando-o com a cabeça para o alto ou com os pés no chão. $\mathrm{O}$ materialismo histórico e a concepção de história em Marx e Engels estão intimamente ligados entre si e ao método dialético.

Em $A$ ideologia alemã, os autores dizem que, longe de partir de pressupostos arbitrários ou dogmas, eles partem dos indivíduos reais, de suas ações e suas condições de vida, para, a seguir, dizer que o primeiro pressuposto de toda a história humana "é naturalmente a existência de indivíduos humanos vivos" e que os seres humanos começam a se diferenciar dos animais "tão logo começam a produzir seus meios de vida" (Marx \& Engels, 1987, p. 26-27. Grifo dos autores). Se a dialética hegeliana se dava no mundo das ideias, a dialética marxista se dá no mundo humano:

Totalmente ao contrário do que ocorre na filosofia alemã, que desce do céu à terra, aqui se ascende da terra ao céu. $\mathrm{Ou}$, em outras palavras: não se parte daquilo que os homens dizem, imaginam ou representam, e tampouco dos homens pensados, imaginados e representados para, a partir daí, chegar aos homens em carne e osso; parte-se dos homens realmente ativos e, a partir de processo de vida real, expõe-se também o desenvolvimento dos reflexos ideológicos e dos ecos desse processo de vida. (Marx \& Engels, 1987, p. 37)

Tem-se, a seguir, a afirmação que se tornou célebre: "Não é a consciência que determina a vida, mas a vida que determina a consciência." (Marx \& Engels, 1987, 
p. 37). E, logo no início do item "História", tem-se a primeira formulação explícita do materialismo histórico, que - acredita-se - tem tudo a ver com a agroecologia:

Em relação aos alemães, somos forçados a começar constatando que o primeiro pressuposto de toda a existência humana e, portanto, de toda a história, é que os homens devem estar em condições de viver para poder "fazer história". Mas, para viver, é preciso antes de tudo comer, beber, ter habitação, vestir-se e algumas coisas mais. O primeiro ato histórico é, portanto, a produção dos meios que permitem a satisfação destas necessidades, a produção da própria vida material, e de fato este é um ato histórico, uma condição fundamental de toda a história, que ainda hoje, como há milhares de anos, deve ser cumprido todos os dias e todas as horas, simplesmente para manter os homens vivos. (Marx \& Engels, 1987, p. 39)

\section{A título de conclusão}

A passagem talvez mais importante em toda a obra de Marx e Engels para se pensar a agroecologia numa perspectiva dialética parece ser a que se encontra no final do capítulo 13 do livro 1 de $O$ capital, onde Marx trata da maquinaria e indústria moderna. Ali ele antecipa alguns resultados de seu estudo sobre a revolução operada pela indústria moderna na agricultura. "Na agricultura", diz ele, "o emprego da maquinaria está, em grande parte, livre dos prejuízos físicos que acarreta ao trabalhador na fábrica, mas atua, de maneira mais intensa e sem oposição, no sentido de tornar supérfluos os trabalhadores"
(Marx, 1998, p. 569). “A indústria moderna”, prossegue ele, "atua na agricultura mais revolucionariamente que em qualquer outro setor, ao destruir o baluarte da velha sociedade, o camponês, substituindo-o pelo trabalhador assalariado" (Marx, 1998, p. 570). E o autor prossegue mostrando como "todo progresso da agricultura capitalista significa progresso na arte de despojar não só o trabalhador, mas também o solo; e todo aumento da fertilidade da terra num tempo dado significa esgotamento mais rápido das fontes duradouras dessa fertilidade" (Marx, 1998, p. 571). Por fim, temos a conclusão de Marx, preocupante e também inspiradora para a agroecologia, especialmente se atualizada em relação aos quase 150 anos que nos separam da publicação do primeiro livro de $O$ Capital:

Quanto mais se apoia na indústria moderna o desenvolvimento de um país, [...], mais rápido é esse processo de destruição. A produção capitalista, portanto, só desenvolve a técnica e a combinação do processo social de produção, exaurindo as fontes originais de toda a riqueza: a terra e o trabalhador. (Marx, 1998, p. 571)

Para encerrar, há que reconhecer que são muitas as vozes que, desde o final dos anos 1980, vêm dando Marx (com sua dialética) como um "cão morto", tal como se fizera antes com Hegel e Espinosa. No entanto, talvez não seja fora de propósito lembrar o alerta do autor de Espectros de Marx quando diz que "um fantasma não morre nunca, está sempre por vir ou retornar" (Derrida, 1994, p. 136). É compreensível, assim, que a dialética marxista desperte tanto temor de parte daqueles que têm a ordem como artigo de fé e repositório de todas as esperanças. 


\section{Referências}

Assis, J. de P. Kuhn e as ciências sociais. Estudos Avançados, 7(19), 133-164, 1993. Disponível em: http://dx.doi. org/10.1590/S0103-40141993000300004

Badinter, E. (Org.). Palavras de homens (1790-1793). Rio de Janeiro: Nova Fronteira, 1991.

Barnes, H. E. (Ed.). An Introduction to the History of Sociology. Illinois: The University of Chicago Press, 1948.

Bastiat, F. A lei. 2. ed. Rio de Janeiro: Instituto Liberal, 1991.

Bedeschi, G. Marx. Lisboa: Edições 70, 1989.

Benoit, L. O. Sociologia comtiana: gênese e devir. São Paulo: Devir, 1999.

Berthelot, J. M. Os novos desafios epistemológicos da sociologia. Sociologia, problemas e práticas, 33, 111-131, 2000. Disponível em: http://dx.doi.org/10.1590/S010340141997000300012

Borsatto, R. S.; Carmo, M. S. Agroecologia e sua epistemologia. Interciência, 37 (9), 711-716, 2012. Disponível em: http:// www.redalyc.org/articulo.oa? $\mathrm{id}=33925502010$

Bynum, W. Introduction. In: Darwin, C. On the Origin of Species by Means of Natural Selection or The Preservation of Favoured Races in the Struggle for Life. London: Pinguin Books, 2009. p. xv-liii.

Calvez. J.-Y. La pensée de Karl Marx. Paris: Éditions du Seuil, 1956.

Campbell, T. Siete teorias de la sociedad. Madrid: Cátedra, 1988.

Carvalho, I. C. M. Epistemologia ambiental de Enrique Leff. Resenha. Ambiente e Sociedade, 8, 2001. Disponível em: http://www.scielo.br/scielo.php?pi$\mathrm{d}=\mathrm{S} 1414-753 \mathrm{X} 2001000800009 \&$ script=sci_arttext

Comte, A. Curso de filosofia positiva. Discursos sobre o espírito positivo. Catecismo positivista. 1. ed. São Paulo: Abril Cultural, 1973. p. 3-302. (Os pensadores, vol. XXXIII).

Comte, A. Sociologia: Conceitos gerais e surgimento. In: Moraes Filho, E. (Org.). Auguste Comte: sociologia. São Paulo: Ática, 1989. p. 53-72.

Comte, A. 1. Importância da filosofia positiva. 2. Lei dos três estados. In: Cruz, M. B. (Org.). Teorias sociológicas. vol. I. Lisboa: Fundação Calouste Gulbenkian, 1989. p. 135-179.
Condorcet, J. A. N. de C. Marquês de. Sobre a admissão das mulheres ao direito de cidadania. In: Badinter, E. (Org.). Palavras de homens (1790-1793). Rio de Janeiro: Nova Fronteira, 1991, p. 43-52.

Condorcet, J. A. N. de C. Marquês de. Esboço de um quadro histórico dos progressos do espírito humano. Campinas: UNICAMP, 1993.

Condorcet, J. A. N. de C. Marquês de. Cinco Memórias sobre a instrução pública. São Paulo: Ed. UNESP, 2008.

Condorcet, J. A. N. de C. Marquês de. Escritos sobre a instrução pública. Campinas, SP: Autores Associados, 2010. (Coleção clássicos da educação / Coordenação deste volume - G. L. Alves).

Cruz, M B. (Org.). Teorias sociológicas. Lisboa: Fundação Calouste Gulbenkian, 1989. Vol. I.

Darwin, C. On the Origin of Species by Means of Natural Selection or The Preservation of Favoured Races in the Struggle for Life. London: Pinguin Books, 2009.

Derrida. J. Espectros de Marx. Rio de Janeiro: Relume-Dumará, 1994.

Durkheim, É. Educação e Sociologia. São Paulo: Melhoramentos, 1967.

Durkheim, É. As regras do método sociológico. 6. ed. São Paulo: Companhia Editora Nacional, 1971.

Elster, J. Marx hoje. Rio de Janeiro: Paz e Terra, 1989.

Ferraro, A. R. Neoliberalismo e políticas sociais: Um pé em Malthus, outro em Spencer. Universidade e Sociedade, 9(20), 21-33, 1999.

Ferraro, A. R. Neoliberalismo e políticas sociais: a naturalização da exclusão. Estudos Teológicos, 45(1), 99-117, 2005. Disponível em: http://periodicos.est.edu.br/index.php/estudos_teologicos/article/view/532

Ferraro, A. R. Quantidade e qualidade na pesquisa em educação, na perspectiva da dialética marxista. Pro-Posições, 23(1), 129-146, 2012. Disponível em: http://dx.doi.org/10.1590/ S0103-73072012000100009

Gomes, J. C. C. As bases epistemológicas da agroecologia. In: Caporal, F. R.; Azevedo, E. O. de (Orgs.). Princípios e perspec- 
tivas da agroecologia. Instituto Federal de Educação, Ciência e Tecnologia do Paraná. Educação a Distância, 2011. p. 13-41. Disponível em: http://wp.ufpel.edu.br/consagro/files/2012/03/ CAPORAL-Francisco-Roberto-AZEVEDO-Edisio-Oliveira-de-Princ\%C3\%ADpios-e-Perspectivas-da-Agroecologia.pdf

Gramsci, A. Cadernos do Cárcere. 2. ed. Rio de Janeiro: Civilização Brasileira, 2001. Vol. 1.

Hobsbawm, E. J. Marx et l'histoire. Paris : Demopolis, 2008. (Hachette Litteratures).

Konder, L. O que é dialética. 27. ed. São Paulo: Brasiliense, 1998.

Kuhn, T. S. A estrutura das revoluções científicas. 3. ed. São Paulo: Perspectiva, 1992.

Löwy, M. Ideologias e ciência social. Elementos para uma análise marxista. São Paulo: Cortez, 1985.

Lukács, G. História e consciência de classe. Estudos sobre a dialética marxista. São Paulo: Martins Fontes, 2003.

Mandeville, B. La fábula de las abejas o los vicios privados hacen la prosperidad pública. 1. ed., 1. reimpr. México: Fondo de Cultura Económica, 2001.

Marshall, G. (Ed.). A Dictionary of Sociology. 2. ed. New York: Oxford University Press, 1998.

Marx, K. Manuscritos econômico-filosóficos. Lisboa: Edições 70, 1989.

Marx, K. O capital. Livro 3, vol. 6. Rio de Janeiro: Civilização Brasileira, 1994.

Marx, K. O capital. Livro 1, vol. 1. Rio de Janeiro: Civilização Brasileira, 1998.

Marx, K. Miséria da filosofia. Resposta à Filosofia da miséria de Proudhon. São Paulo: Centauro, 2006.

Marx, K.; Engels, F. Ideologia alemã. (Feuerbach). 6. ed. São Paulo: HUCITEC, 1987.

Mendras, H.; Étienne, J. Les grandes auteurs de la sociologie: Tocqueville, Marx, Durkheim, Weber. Paris: Hatier, 1996.

Mill, J. S. Autobiografia. Madrid: Alianza, 1986.

Millizo, C. Prólogo. In: Mill, J. S. Autobiografía. Madrid: Alianza, 1986. p. 7-30.

Moraes Filho, E. (Org.). Auguste Comte: sociologia. São Paulo: Ática, 1989.
Popper, K. Lógica das ciências sociais. Rio de Janeiro: Tempo Brasileiro, 1978.

Popper, K. A lógica da investigação científica. São Paulo: Abril cultural, 1980. (Os pensadores).

Reale, G.; Antiseri, D. História da Filosofia. 2. ed. São Paulo: Paulus, 1991. Vol. 3.

Saint-Simon, H. Du système industriel. Paris: Renouard, 1821. Disponível em: http://archive.org/stream/dusystmeindustr00saingoog\#page/n9/mode/2up

Sarup, M. Marxismo e educação: abordagem fenomenológica e marxista da educação. Rio de Janeiro: Zahar, 1980.

Schlindwein, S.; Pinheiro, S.; Martins, S. A epistemologia da agroecologia e suas implicações práticas para o desenvolvimento rural: uma proposta metodológica. Revista Brasileira de Agroecologia, 2(2), 384-388, 2007. http://www. aba-agroecologia.org.br/revistas/index.php/rbagroecologia/ article/view/7462

Sevilla Gusmán, A perspectiva sociológica em Agroecologia: uma sistematização de seus métodos e técnicas. Agroecologia e Desenvolvimento Rural Sustentável, 3(1), 18-28, 2002. Disponível em: http://www.emater.tche.br/site/multimidia/ leitor/10.php\#book/17

Smith, A. Inquérito sobre a natureza e as causas da riqueza das nações. Lisboa: Fundação Calouste Gulbenkian, 1987 (vol 1) e 1989 (vol. 2).

Spencer, H. Ensayos sobre Pedagogía. Madrid: Akal, 1983.

Spencer, H. A evolução superorgânica. In: Cruz, M. B. (Org.). Teorias sociológicas. Lisboa: Fundação Calouste Gulbenkian, 1989. Vol. I., p. 181-231.

Stallybras, P. O casaco de Marx: roupas, memória, dor. Belo Horizonte: Autêntica, 1999.

Sztompka, P. A sociologia da mudança social. Rio de Janeiro: Civilização Brasileira, 1998.

Tort, P. Spencer et l'évolutionisme philosophique. 1. ed. Paris : Presses Universitaires de France, 1996.

Tort, P. Darwin et le darwinisme. Paris : Presses Universitaires de France, 1997. 